SHS Web of Conferences 12, 01076 (2014)

DOI: $10.1051 /$ shsconf/ 20141201076

(C) Owned by the authors, published by EDP Sciences, 2014

\title{
Human Resource Management Practice Tourism and Hotel Industry
}

\author{
S.A. Al Hrout ${ }^{1}$, B. Mohamed ${ }^{2}$ \\ ${ }^{1,2}$ School of Housing, Building and Planning, Universiti Sains Malaysia, 11800, Penang, Malaysia \\ ${ }^{1,2}$ Sustainable Tourism Research Cluster, Universiti Sains Malaysia, 11800, Penang, Malaysia
}

\begin{abstract}
Due to the importance of human resources management (HRM) in promoting competitiveness in tourism and hotel industry, this review intend to enhance the understanding of practical issues of HRM more importantly since it involve organizing the management of human resources, with respect to accomplishment of organizational objective further more it shows that the issues either related to external factors, which include technological change, legislation and regulation, and national culture, globalization, or internal factors including size, industry and sector characteristic and structure of an organization, strategy and past practice of HRM. On the issue of human resources capability training, this research review recommend provision of array of opportunity for capability building and conducive working environment to promote productivity. Also worth considering, employee, employer relationship, Other variables such as attitude and productivity of employees, relationship between employees and employers, increase and decrease in financial assets should be taken into account.
\end{abstract}

\section{Introduction}

Professionalism, manpower development and frequent motivation are the cardinal drive towards successful hotel business [1]. Regular training of frontline personnel in the area of communication skill goes a long way in upgrading the frontline staff in their service delivery to their prospective customers [2] which ensures competence skills as well as professional skills.

Lack of adequate training among the hotel staff has been counterproductive [3] because this has often resulted into low performance and commitment in the hotel business. Conversely, Human resource practice (HRP) development which involve regular staff training, is an important factor of HRM which has to be formally entrenched in the modus operandi in an organization [4] although very few organization pay due attention to this fact.

The aim of this research work is therefore to investigate the factors contributing to the unsuitable practices of HRP in some selected hotels according to the hotel management in order to unravel the challenges faced HRP as it is poorly implemented [5]. The need by the hotel management to carry out regular training was reported by [6] this will ensure staff professionalism. Apart of being a complimentary tool for good management, HRM training promotes productivity of the service and helps in organizational stability [7]. 
Equipping hotel employees with the skills that are necessary for performing their job. Is very important therefore, service line workers should be well-trained to get skillful, which gives good services to hotel customers. This might run contrary to the principle of human resource practices (HRPs) this has been seen to reduce the productivity and performance of hotel staff.

Human resource practices (HRPs) is very important as hotel image makers between the hotel management and the customers hence regular training and assessment of the staff human resources is essential. The employer's approach to HDPs is a key driving factor in improving the expertise and productivity of the hotel staff. This will lead to improve income to the hotel staff and management through continue patronage enjoyed and the country as a whole through the fulfillment of their civic responsibility.

It is worth reporting the that due to lack of adequate infrastructures, some HR staff in the hotel industry are not properly skilled. This has grossly affected the workers productivity [8]. The effect of the few trained Staff from the HR will be investigated with the performance index with respect to the company's HRD and HR with aim of solving the present challenges being faced and improving their service delivery.

This will serve as a yardstick to formulate a better HR strategy to overcome the present challenges being face in the industry. However this will improve the hotel staff's productivity and equally improve the performance index of the staff from their present status.

\section{Factors Affecting HRM Practices}

Despite the fact that HRM practices vary from one country to another, factors affecting it could be divided into two via- internal and external factors. These factors as it affect the HRP differ significantly across countries [7]. Meaning that this is still governed by some underlying factors as follows:

\subsection{External Factors}

According to [9], some factors affecting HR practices are long term. these factors include:

\subsubsection{Economic Internationally Changes}

HR practices has become more and more significant due to the gradual development of global economy [10]. The scope of HR has taken global and international dimension.

\subsubsection{Technological Changes}

Technology affects HRM to the extent that the performance and perspective of technological development modify the HR practices. National Culture culture plays a key role in organization preferences in the appropriate structure and method development for HR practice affectivity [11].

The degree of interaction between technology and HR affect the ways we work, the roles we undertake, and the interactions through which work gets done [12], facilitates the growth of a multinational enterprise [13] and also generates simultaneous challenges among a geographically dispersed workforce. It could be concluded that technology has a lot of business advantage and is the nucleus industrial growth [6]. 


\subsubsection{Industry/Sector Characteristics}

In agreement with the opinion of [9] which states that in an organization, HR practices is differentiated by classification based on manufacturing and service organizations which is often used for analyzing the HRM practices.

\subsubsection{Legislations /Regulations}

[9] equally opined that HR practices are directly correlated with Legislations and regulations. Since a set of regulations of HRM is developed by every country, the HRM practices have to be planned and adapted to suit these regulations.

\subsubsection{Actions of Competitors}

Development of comprehensive HRPs is one of the many way of which companies can gain a competitive edge or a lasting and sustained advantage over their competitors [14].

\subsubsection{Action of Unions}

Unionism is another important factor that has a correlation with HR of some organization.

\subsubsection{Globalization}

Another challenge facing organizational HR management is globalization which has rendered the global market as a single entity. HR activities has gone trans boundaries resulting in cross border exchange of HR management. More importantly, this has been paving way to modify and become practicable in another setting.

A synthesis of the review of literature is presented at the end of the paper. Sequel to the various reviews by researchers on the development of the conceptual framework, it has been reported that relationship between HRM practices and other important organizational variables is them presented along with Indian companies as practices in HR [15]. The next section of the current paper will discuss the types of HRM practices, followed by the detailed discussion of factors affecting HRM practices and various models of HRM practices.

The subsequent section will be evaluating the factors affecting HRM, the model and the types of HRM practices

\subsection{Internal Factors}

Among the variety of list compiled of organizational characteristic related to HR, internal factors plays a prominent role [16] as follows:

\subsubsection{Organizations Size}

Since there is a need for a different HR department [17], there is a large number of small firms which hardly institute formal HR practices in large organizations , at each functional level [18].

\subsubsection{Organizational Structure}

The design and operation of HR varies from one A firm to the other [19]. Structure and strategy and are important to determining HR practice flexibility and integration. 


\subsubsection{Business Strategy}

Business environment can be improved by making efficient choices about human resource practices that consistently support their select strategy [16]. In order to achieve this competitive advantage, more productive correlated to HRM practices are used with different competitive strategies.

\subsubsection{Human Resource Strategy}

HR practices are fashioned according with the HR strategy [20]. Strongly related factors, such as history, traditions and past practices tend to generate resistance to change in most organizations [21].

\subsubsection{Top Management}

The importance of the top management on HR practices in designing and implementation [9] is well known by most analyst and documented in the literature.

\subsubsection{Line Management}

Apart from the top management, the line Management involvement in designing and implementing HR activities through the creation of values is equally important for any reasonable breakthrough in an organization [22].

\subsubsection{Power and Politics}

HR practices are usually influenced by organizational power and politics [23].

\subsubsection{Academic and Professional influence on HR Practices}

The valuable contributions of the academician and professionals on HR staffs are often well appreciated [9].

\section{Conclusion}

In the age of globalization and liberalization alongside tremendous development in service sector has transformed the world around us. These advancements have brought tourism industry to centre stage of importance where the human resources management and human resources developments are being thought as a pinpoint issue for proper service.

The point of human resource management (HRM) and human resources development (HRD) is to make sure fitting deployment of human resource so that the quality of culture is maintained and the customers are satisfied not only in local context but also in global level. In competitive situation of current business environment, effective and efficient utilization of human capital has become utmost priority.

The preliminary assignment of every business nowadays is to identify, recruit, channel and incorporate skilled human resources into their operations in order to improve productivity and increase functional efficiency. Apparently, the tourism industry is a rapidly growing industry which has been abundant and profitable across the world, engaging organizers and agencies that are in charge of tourist services. Each stakeholder requires thousands of staff to work efficiently. 
The tourism characteristics, its key concepts, and factors fostering relationships between tourists, tour organizers, governments and local communities were mostly focused in this particular study. More specifically this research analysed the pro-social behaviour of the employees in Malaysian tourism and hospitality industry in general and the front-line staff in particular to see how the behaviour is linked to hotel industry and can promote the quality of the services offered by them.

\section{References}

1. G.N Chandler, and G. M. McEvoy, "Human Resource Management, TQM, and Firm Performance in Small and MediumSize Enter pr ises", Entrepr eneur ship: Theor y and Practice, 25, 1,43-58 (2000)

2. N. Khatri, Emerging issues in Strategic HRM IN Singapore “, International Journal of Manpower, 20, 8, 516-529 (1999)

3. M.J Koch, and R.G McGrath, 'Improving Labor Productivity: Human Resource Management Policies Do Matter', Strategic Management Journal, 17, 335-54 (1996)

4. S.J Rundle, "Flexibility, adaptiveness and responsiveness (FAR-ness) as the key success factors in market entry in the south east Asian growth wedge ", $\mathrm{PhD}$ thesis,Department of Management, Monash University,Victoria.(1997)

5. Saxena Karunesh \& Tiwari Pankaj, "A Study of HRM Practices in Selected IT Companies of India”, AIMS Journal of Management, 1, 3, 29-44. (2009)

6. T.N Garavan, J.P Wilson, C. Cross and R. Carbery R, "Mapping The context and Practice of Training, Development and HRD IN European Call Centers “, Journal of European Industrial Training, 32, 8, 612-728. (2008)

7. H. Ozutku and H. Ozturkler, "The Determinants of Human Resource Practices: An Empirical Investigation in the Turkish Manufacturing Industry”, Ege Academic Review, 9, 1, 73-93. (2009)

8. Kok Jan de, Kumar Thurik Roy \& Ulhaner Lorraine (2003), "Professional HRM Practices in Family Owned-Managed Enterprises", Scales PaperN200319,EIM and Erasmus University Rotterdam (CASBEC), Zoetermeer, December 2003.

9. B. Kane, and I. Palmer, “Strategic HRM or Managing Employment Relationship? ”,International Journal of Manpower, 16, 5, 6-21 (1995)

10. T. Satow and Z.M Wang, "Cultural and Organisational Factors in Human Resource Management in China and Japan”, Journal of Managerial Psychology, 9, 4, 3-11. (1994)

11. A. Chandrakumara, and P. Sparrow, "Work Orientation as an Element of National Culture and Its Impact on HRM Policy-Practice Design Choices”, International Jour nal of Manpower, 25, 6, 564-589. (2004)

12. R.J DeFillippi, “Organisational Models for Collaboration in New Economy”, Human Resource Planning, 25, 4, 7-18. (2002)

13. F. Verkinderen, \& Y. Altman, "Leisureplanet.com - Organization and HRM in the New Economy” Human Resource Planning, 25, 4, 19-29. (2002)

14. S. Narsimha, "Organisational Knowledge, Human Resource Management and Sustained Competitive Advantage: Towards A Framework”, Competitiveness Review, 10, 1, 123-136. (2000)

15. F. Verkinderen, \& Y. Altman, "Leisureplanet.com - Organization and HRM in the New Economy” Human Resource Planning, 25, 4, 19-29. (2002)

16. G.T Milkovich, and J.W Boudereau, "Human Resource Management,USA: Richard D.Irwin,Inc. (1991)

17. S.E Jackson, R.S Schuler and J.C Rivero,J.C. “Organisational Characteristics As Predictors of Personnel Practices”, Personnel Psychology, 42, 4, 727-786 (1989)

18. M. McPherson,M, "HRM Practices and Systems within South Asian Small Business", International Journal of Entrepreneurial Behavior \& Research, 14, 6, 414-439. (2008)

19. D.A Gr avin, “What does Product Quality really mean?",Sloan Management Review, 25-43. 
(1986)

20. T.N Garavan, J.P Wilson, C. Cross and R. Carbery, "Mapping The context and Practice of Training, Development and HRD IN European Call Centers “, Journal of European Industrial Training, 32, 8, 612-728. (2008)

21. M. Pardo, and C.M Fuentes, "Resistance to Change: A Liter atur e Review and Empirical study", ManagementDecisions, 41, 2, 148-155. (2003)

22. R. Alas, T. Karrelson, and K. Niglas, "Human Resource Management in Cultural Contxet: Empirical Study of 11 Countries", EBS Review, 24, 1, 49-63. (2008)

23. A.S Tsui, and GT.T Milkovich, "Personnel Department Activities : Constituency Perspectives and Preferences”, Personnel Psychology, 40, 519-537. (1987) 